\title{
Use of Dual Polarisation Interferometry as a diagnostic tool for protein crystallisation
}

Attia Boudjemline ${ }^{\mathrm{a}}$, Emmanuel Saridakis ${ }^{\mathrm{b}^{*}}$, Marcus J. Swann ${ }^{\mathrm{a}^{*}}$, Lata Govada ${ }^{\mathrm{c}}$, Irene M. Mavridis ${ }^{\mathrm{b}}$, Naomi E. Chayen ${ }^{\mathrm{c}^{*}}$

${ }^{\mathrm{a}}$ Farfield Group Ltd, Manchester M90 3DQ U.K. ${ }^{\mathrm{b}}$ Institute of Physical Chemistry, N.C.S.R. "DEMOKRITOS”, Athens 15310, Greece "Biomolecular Medicine, Dept. of Surgery and Cancer, Faculty of Medicine, Imperial College London, SW7 2AZ, U.K.

\section{Abstract}

The use of Dual Polarization Interferometry (DPI) as a tool for probing the different possible outcomes of protein crystallisation experiments is described. DPI is a surface analytical technique used for the characterisation of structure and interactions of molecular layers on an optical waveguide surface for a wide range of applications, including protein-protein interactions and conformational changes. The application of this technique provides a 'signature' of crystallisation events thus predicting if there will be protein crystal formation, amorphous precipitate or clear solution. The technique was demonstrated on a number of model proteins and it also produced meaningful results in the case of two problematic target proteins. DPI in conjunction with a dialysis setup, allows changes in the protein solution above the waveguide surface to be monitored simultaneously with continuous control of its precipitant content. DPI has the potential to be used as a powerful method for discovering crystallisation conditions, for obtaining information on the crystallisation process and as an aid in crystal optimisation. It has also provided what is, to the best of our knowledge, the most direct observation to date of salting in behaviour in a protein-salt solution.

\section{Introduction}

X-ray crystallography is the most widely used method for elucidating the threedimensional structures of biological macromolecules. It is the only method that allows 
macromolecular structures to be solved up to atomic resolution and without a priori limitations on the size of the molecules. Success in crystallographic structure elucidation depends absolutely on success in obtaining well-diffracting crystals of the molecule or complex. This is a protracted process which is often unsuccessful. The great numbers of conditions that usually need to be blindly tried before promising results can be observed (if at all) and the corresponding requirements in large quantities of pure, highly concentrated macromolecular material, consumables, labour and incubation times, is a major stumbling block to the process ${ }^{1}$. The problem is compounded by the fact that a condition which is close to success can be easily missed if the value of one of the parameters is even slightly outside the region where crystalline material would be distinguishable under a stereoscope.

In this paper, we report the use of Dual Polarization Interferometry (DPI) as an effective diagnostic tool for protein crystallisation, which enables the early and efficient detection of conditions that are most likely to lead to crystals, more quickly and economically than by conventional screening. DPI is an optical waveguide technique which has been widely used for the measurement of the dimensions of surface molecular layers and their interactions $\mathrm{s}^{2-4}$. The technique monitors the change of the velocity of propagation of two polarisations of light down a waveguide by measuring the change in the respective interference patterns output from the device. The interference is generated between an upper sensing and a buried lower reference waveguide as shown in Figure 1. Any change in the refractive index (RI) above the waveguide surface will change the velocity of propagation of the light and so change the phase position of the two sets of interference fringes.

In general use, the phase changes are monitored, whereas the sharpness of the fringe pattern, i.e. contrast, which is related to the amount of light propagating along the waveguide, is not observed to change significantly. The contrast can however be expected to change due to loss of light from the waveguide, either because of optical absorption or by the presence of surface structures that scatter or couple light out of the waveguide. This latter effect has recently been shown to occur as a result of protein crystallisation ${ }^{5}$. Specifically, it had been shown that DPI enabled the real-time detection of early protein crystallisation events. Experiments were run using a batch method. The crystallisation solution was in contact with the 'sensing' waveguide and 
the measured phase shift and contrast ratio of the interference fringes were shown to be sensitive to the deposition of a protein adlayer on the sensing waveguide and to crystallisation events at or near the solution-waveguide interface. Namely, a rather sharp drop in contrast accompanying the phase shift was observed at crystallisation conditions. However, the routine use of batch crystallisation with this technique has severe limitations. Only a limited amount of discrete trials can be performed and promising conditions can still easily be 'missed' in spite of the improved detection, because the concentration of an otherwise promising precipitant, or of the protein, might be already far too high at the outset. Furthermore, if precipitate has already formed in the solution bulk upon mixing and before insertion into the measurement cell, no signal (which is dependent on the deposition of protein or crystals on the waveguide) will be obtained. Therefore, the method has been adapted to dialysis, by effectively splitting the chamber in the horizontal direction by interposition of a dialysis membrane.

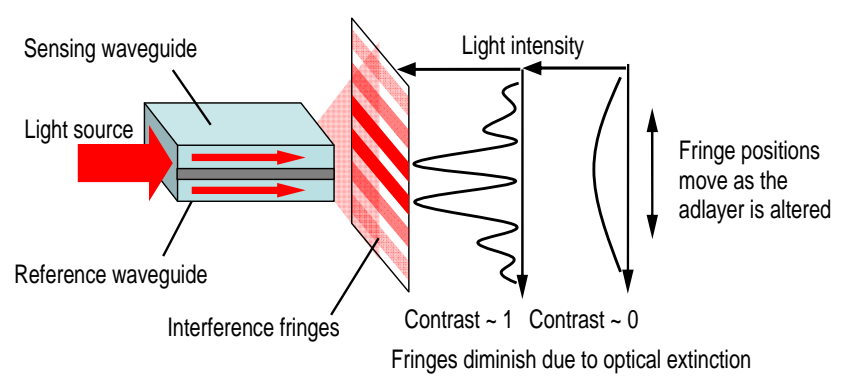

Figure 1. Optical principle of Dual Polarisation Interferometry. Light from a sensing waveguide in contact with the investigated solution interferes with that from a reference waveguide, resulting in interference fringes characterised by their phase and contrast.

In the present study we implemented DPI in a dialysis setup and applied it to five proteins, under crystallisation and non-crystallisation conditions. Lysozyme, catalase and thaumatin were used to validate the technique, and dynamin and xylanase were target proteins for which finding crystallisation conditions had proved to be problematic, thus it was needed to test if DPI would give an indication of whether crystallisation would take place. A dialysis approach enabled us to scan across a wide range of conditions (precipitant, $\mathrm{pH}$ etc.), continuously or step-wise, in one trial. We have examined in detail the differences between DPI measurements from crystallising 
versus non-crystallising (clear and amorphously precipitating) protein solutions and have found what seems to be an unequivocal 'signature' of crystallisation events, which were also detected by direct microscopic observation. Dialysis experiments were set up at conditions known to lead to clear solutions, to crystallisation and to precipitation, as described below. The DPI dialysis method can be used to discriminate between the formations of crystalline versus amorphous material in real time as a function of precipitant concentration. Real-time DPI monitoring of such a trial can therefore indicate whether this particular precipitant or precipitant/buffer combination is worth pursuing and optimising for crystal production, as well as providing information for establishing a crystallisation phase diagram.

\section{Materials and Methods}

\section{Description of the DPI apparatus and crystallisation cells.}

The principles of construction and operation of the DPI apparatus are described in the Supporting Information.

A special dialysis cell was constructed, to fit the DPI instrument (Analight Bio200, Farfield Group Ltd, Crewe, UK), as shown schematically in Figure S1 (Supporting Information). Above the optical waveguide chip surface a gasket with a cut-out channel was placed, which defined the sample sensing area above the chip. An inlet and an outlet allowed protein solution to be flowed through this channel, in contact with the sensing waveguide. Above this protein channel was bonded a defined pore size filter membrane (Millipore UK, Ultracell Ultrafiltration Disc, 5000 Molecular Weight cut-off, or 10000 MWCO for PEG solutions), above which a polyether ether ketone (PEEK) manifold block was clamped with a corresponding dialysis channel machined into it and provided with its own inlet and outlet tubing. The protein and dialysis channels were isolated from each other by the sandwiched membrane. This setup enabled independent solutions to be flowed either over the chip surface, or through the dialysis channel. This arrangement was duplicated to allow two side-byside experiments to be performed at any one time. Presently, one of the fluidic setups was used to perform a control experiment without protein. The channels are $15 \mathrm{~mm}$ long, with a width of $1 \mathrm{~mm}$ and depth of $0.5 \mathrm{~mm}$. The volume of liquid contained in 
the channel is therefore $7.5 \mu \mathrm{l}$ but the loading routine and dead volumes used meant that $20 \mu \mathrm{l}$ of protein sample had to be used per run. Subsequent developments have reduced the minimum volume of protein solution to approximately $10 \mu 1$ per run.

The bottom channel, in contact with the sensing waveguide, is filled with the protein solution (hence the 'protein channel'), whereas the precipitant solution is injected into the higher channel ('dialysis channel') above the membrane. The precipitant solution can be either kept fixed in the upper part of the chamber for the whole duration of the trial, or replenished continuously or periodically, or it can be modified in response to the DPI measurements that are recorded during the trial. This has been achieved using an autosampler (Jasco AS-2055).

An observation cell was also constructed, with the same geometry and dimensions as the measuring cell, in order to allow observation under the stereoscope of an identical experiment run outside the Analight instrument. In this case the sensor chip and fluidic block are replaced with glass plates.

\section{Crystallisation and control experiments}

Details of the proteins and chemicals used are provided in the Supporting Information.

Due to the presence of the membrane and to the dialysis delay time, the precipitant concentration at the chip surface had to be determined by a calibration procedure, described in the Supporting Information. This calibration was used to convert from plots of phase shift and contrast against time, to plots against calibrated salt concentration (e.g. Figure 2).

The chip temperature was controlled using a two-stage Peltier thermoregulator built into the Analight instrument, which allows control between 15 and $40^{\circ} \mathrm{C}$ with an accuracy of approximately $0.5^{\circ} \mathrm{C}$. All experiments were carried out at $20^{\circ} \mathrm{C}$.

Lysozyme. Different lysozyme solutions $(5,10,20$ and $30 \mathrm{mg} / \mathrm{ml})$ in $50 \mathrm{mM}$ sodium acetate at $\mathrm{pH} 4.6$ were dialysed against same buffer solutions of $\mathrm{NaCl}$ concentrations 
varying from $1 \%$ to $20 \%(\mathrm{w} / \mathrm{v})$. The salt solutions were injected into the precipitant channel in $1 \%(\mathrm{w} / \mathrm{v})$ increments for 20-30 minutes each (Table 1$)$.

Catalase. A catalase solution in $100 \mathrm{mM}$ Tris at $\mathrm{pH} 7.5$ was dialysed against a $30 \%$ (w/v) PEG 6000, 5\% (v/v) MPD solution in the same buffer. The PEG dialyses slowly through the 10000 Molecular Weight cut-off membrane and therefore the protein solution is exposed to a continuous range of PEG concentrations, without the need to step up by successive precipitant injections. Two experimental runs were performed with protein concentrations of $12 \mathrm{mg} / \mathrm{ml}$ and $14 \mathrm{mg} / \mathrm{ml}$ (Table 1), corresponding to the crystallisation range of conditions for catalase ${ }^{6,7}$. These were also checked by setting up parallel experiments, initially in microbatch under oil and later in the observation cell. A catalase trial leading to clear solution $(14 \mathrm{mg} / \mathrm{ml}$ protein dialysed against $30 \%(\mathrm{w} / \mathrm{v}) \mathrm{NaCl})$ was also performed.

Thaumatin. Three types of experiment were run (Table 1):

(i) At well-known crystallisation conditions, ranging from $10 \mathrm{mg} / \mathrm{ml}$ to $25 \mathrm{mg} / \mathrm{ml}$ thaumatin in $50 \mathrm{mM}$ PIPES buffer at $\mathrm{pH} 6.8$, dialysed against sodium potassium tartrate at concentrations from $0.1 \mathrm{M}$ up to $2 \mathrm{M}$ in the same buffer ${ }^{8}$.

(ii) At conditions similar to ones reported in the literature to produce crystals, 40 $\mathrm{mg} / \mathrm{ml}$ protein in $50 \mathrm{mM}$ PIPES buffer, $\mathrm{pH} 6.8$, dialysed against $0.5 \mathrm{M}$ to $3 \mathrm{M}$ ammonium sulphate ${ }^{9,10}$. However, these only produced precipitate when tried in the observation cell.

(iii) At conditions leading to amorphous precipitation, $16 \mathrm{mg} / \mathrm{ml}$ thaumatin in 50 $\mathrm{mM}$ PIPES, $\mathrm{pH} 6.8$, dialysed against $0.5 \mathrm{M}$ to $2.5 \mathrm{M}$ sodium chloride. These conditions have never been reported to yield thaumatin crystals and they have also been verified in our laboratory to give rise to amorphous precipitate.

Rat Dynamin. Protein at a stock concentration of $4.5 \mathrm{mg} / \mathrm{ml}$ in $20 \mathrm{mM}$ PIPES, 20 mM HEPES, $\mathrm{pH}$ 7, with 1mM EGTA, $150 \mathrm{mM} \mathrm{NaCl}, 2 \mathrm{mM} \mathrm{MgCl}_{2}$ and $5 \mathrm{mM}$ dithiothreitol was dialysed against the same buffer solutions with $\mathrm{NaCl}$ concentrations varying from $150 \mathrm{mM}$ to $2 \mathrm{M}$. 
Xylanase. Protein at $12 \mathrm{mg} / \mathrm{ml}$ in a buffer of $20 \mathrm{mM}$ Tris $\mathrm{HCl}$ at $\mathrm{pH} 7$ and $100 \mathrm{mM}$ $\mathrm{NaCl}$ was dialysed against a buffer of $0.1 \mathrm{M}$ sodium cacodylate at $\mathrm{pH} 6.5$ and $100 \mathrm{mM}$ $\mathrm{NaCl}$ with ammonium sulphate concentration varying from 0 to $2.8 \mathrm{M}$.

\section{Results and Discussion}

\section{Discrimination of crystallising versus non-crystallising protein solutions}

Lysozyme. In order to benchmark the technique and validate the practical process, experiments were first performed using lysozyme. Four different trials at varying protein concentrations were run (Table 1). In all cases, it was observed that, in the earlier stages of the dialysis (Figures 2 and S2, Supporting Information), the phase shift of the protein solution dialysing against $\mathrm{NaCl}$ was smaller than that in the buffer solution. We believe this region of slower phase change to correspond to the salting in region ${ }^{11}$, where salt binds the protein molecules thus preventing them from forming aggregates in solution and also possibly reducing and reversing their electrostatically driven physisorption on the waveguide surface. Thus at low $\mathrm{NaCl}$ concentrations, lysozyme that is initially adsorbed to the surface upon initial injection (Figure S2, Supporting Information) starts desorbing due to the electrostatic shielding of the salt. Because the phase change due to the increasing bulk contribution from the salt is higher than the contribution from the desorbing protein, the phase does still increase, but at a lower rate than observed for the control channel. As the amount of salt increases further, more protein starts depositing on the surface, leading to a net increase in the phase change above that observed for just salt: this corresponds to the onset of salting-out. This is, to the best of our knowledge, the most direct observation to date of salting in behaviour and the transition from salting-in to salting-out in a protein-salt solution. 


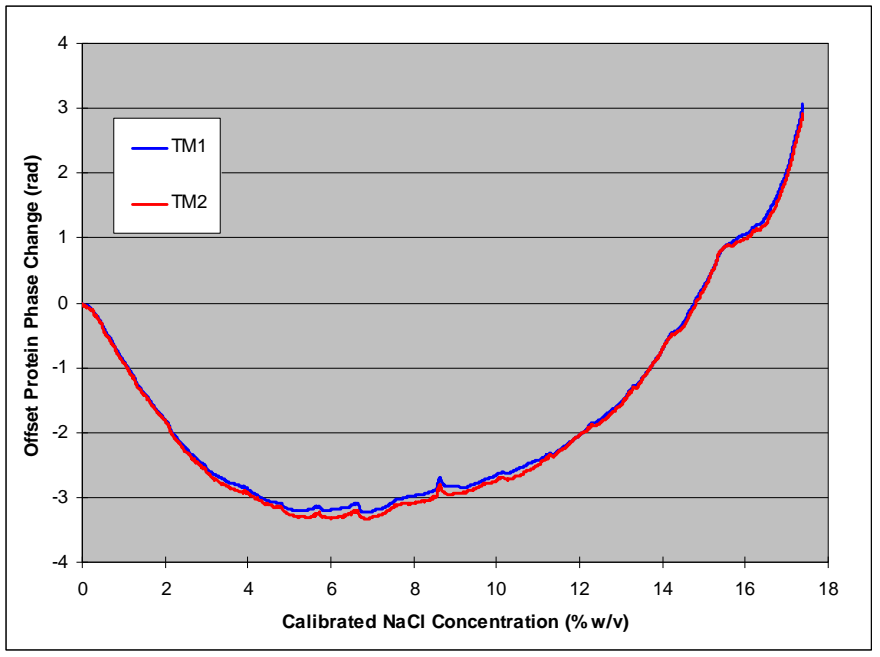

Figure 2. Early stages of an experiment with lysozyme $(5 \mathrm{mg} / \mathrm{ml})$ dialysed against sodium chloride $(0-11 \%(\mathrm{w} / \mathrm{v})$. Difference in phase change between the protein channel and the control (buffer) channel as a function of calibrated salt concentration. The negative change at low concentrations indicates a slower phase shift for the protein solution as compared to the buffer. The two traces are measurements of TM phase changes at different positions within the protein channel.

The trial at $5 \mathrm{mg} / \mathrm{ml}$ lysozyme displayed a gradual phase shift and no drop in fringe contrast. Indeed, we always observe $5 \mathrm{mg} / \mathrm{ml}$ lysozyme solutions to remain clear throughout the tested range of $\mathrm{NaCl}$ concentrations.

The other three trials, with more concentrated protein $(10-30 \mathrm{mg} / \mathrm{ml})$, displayed a sharp increase in phase approximately coinciding with a very sharp drop in the fringe contrast (Figure 3), at different calibrated salt concentrations: the more concentrated the protein solution, the lower the salt concentration at which the discontinuity occurred, as expected, since more concentrated protein solutions need less salt to reach supersaturation and spontaneous nucleation conditions. 


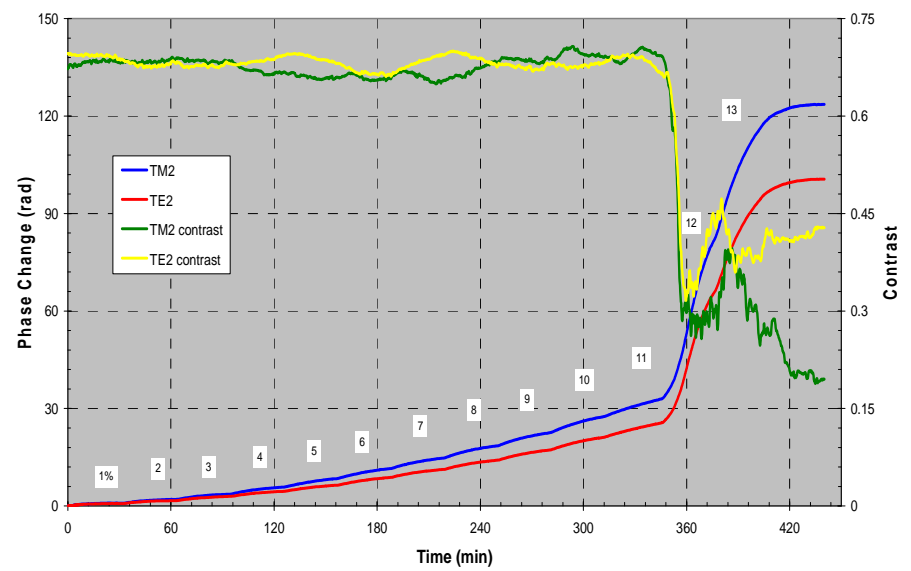

Figure 3. TM and TE phase shifts and contrasts for a $30 \mathrm{mg} / \mathrm{ml}$ lysozyme solution dialysed against $\mathrm{NaCl}$, versus time. The injected $\mathrm{NaCl}$ concentrations $(1-13 \%(\mathrm{w} / \mathrm{v}))$ are indicated in white boxes above the phase shift curves. The control channel measurements are not shown.

Catalase. Both experimental runs, at $12 \mathrm{mg} / \mathrm{ml}$ (Figure S3, Supporting Information) and at $14 \mathrm{mg} / \mathrm{ml}$ catalase, displayed a marked increase in phase in tandem with a sharp loss of contrast at crystallisation conditions, as opposed to runs performed at conditions leading to clear solutions (Figure S4, Supporting Information). The latter led to a very small phase increase over and above the $\mathrm{NaCl}$ solution alone, due to a low level of protein deposition on the chip, and to no loss of contrast.

Thaumatin. Three experimental runs at various thaumatin concentrations were performed at sodium potassium tartrate conditions in the presence of PIPES at $\mathrm{pH} 6.8$, which are the most common conditions for thaumatin crystallisation (Table 1). All runs showed an increase in phase coupled with an abrupt loss of contrast.

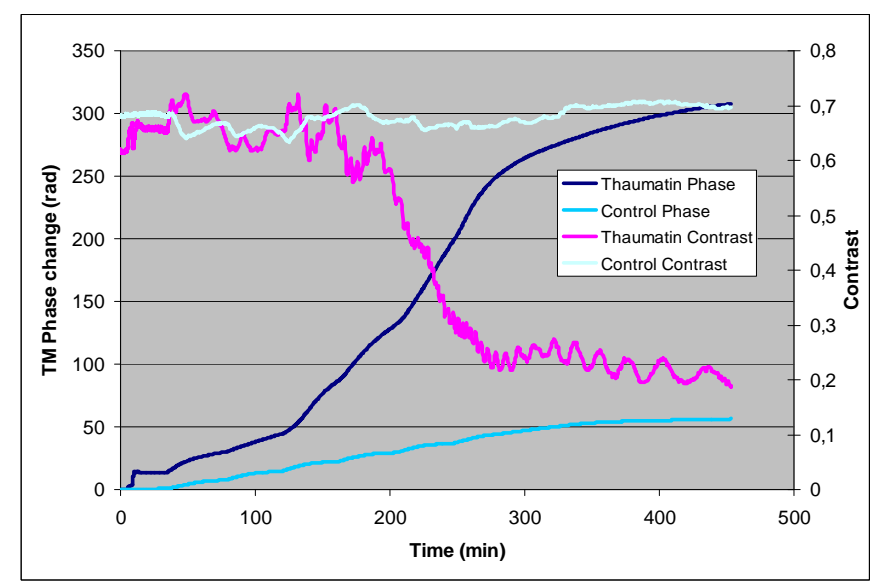

Figure 4. Phase and contrast for a $40 \mathrm{mg} / \mathrm{ml}$ thaumatin solution in PIPES, $\mathrm{pH}$ 6.8, dialysed against 0.5 to $3 \mathrm{M}$ ammonium sulphate. 
Two more runs performed without tartrate, in which $40 \mathrm{mg} / \mathrm{ml}$ protein was dialysed against 0.5 to $3 \mathrm{M}$ ammonium sulphate in the same buffer (Figure 4) produced similar results as with sodium tartrate, i.e. an increase in phase accompanied by loss of contrast, though not as sharp as in the tartrate experiments. Although it was not expected that thaumatin would crystallise without tartrate, similar crystallisation conditions had in fact been reported in the past $(20 \mathrm{mg} / \mathrm{ml}$ protein, 2-2.5 M ammonium sulphate, $50 \mathrm{mM}$ HEPES, $\mathrm{pH} 7.0$, at $20^{\circ} \mathrm{C}$ in vapour diffusion ${ }^{9,}{ }^{10}$ ). Standard vapour diffusion hanging drop trials were set up around these conditions for verification and produced microcrystals when $20 \mathrm{mg} / \mathrm{ml}$ protein was mixed in equal volumes $(2 \mu \mathrm{l}+2 \mu \mathrm{l})$ and equilibrated against a solution of $0.75 \mathrm{M}-1.0 \mathrm{M}$ ammonium sulphate in $50 \mathrm{mM}$ HEPES, $\mathrm{pH} 7.0$, at $20^{\circ} \mathrm{C}$. This result exemplifies the usefulness of DPI in "discovering" what was in fact to us an "unknown" crystallisation condition and showing that we were in fact working very near crystallisation conditions (but presumably at too high supersaturation) .

Two runs were also performed at conditions known to induce amorphous precipitation. They consisted of $16 \mathrm{mg} / \mathrm{ml}$ protein in PIPES, $\mathrm{pH}$ 6.8, dialysed against 0.5 to $2.5 \mathrm{M}$ sodium chloride in the same buffer. In both cases, the phase shift was not accompanied by contrast loss (Figure 5). Immediately after the end of the first run, the DPI cell was dismantled and the protein solution inside was examined. It was observed that moderate precipitation had already taken place. In the second run, the dialysis was reversed after reaching the maximum salt concentration, i.e. the protein solution was dialysed against buffer. This resulted in a reduction in the phase shift attributable to the salt. However most of the additional phase change due to protein aggregation was not eliminated, indicating that a large portion of the protein was not redissolved (approximately 80\%) and had been irreversibly deposited. This indicates that the reversibility of the deposition process can be assessed with this method, which potentially provides an additional means of discriminating between forms of deposited material. 


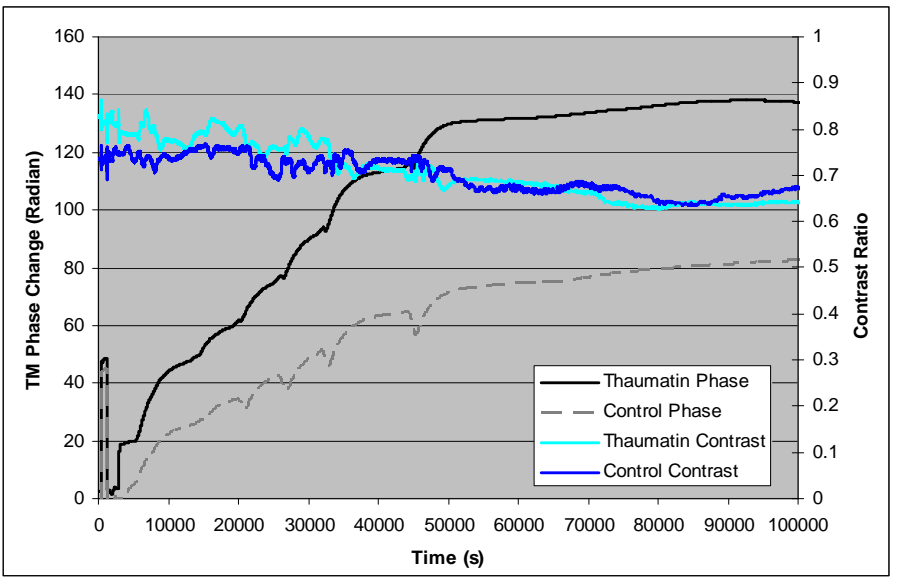

Figure 5. Phase and contrast for a $16 \mathrm{mg} / \mathrm{ml}$ thaumatin solution in PIPES pH 6.8, dialysed against $0.5-2.5 \mathrm{M} \mathrm{NaCl}$ in the same buffer. Under these conditions the protein precipitates amorphously.

\section{Trials with problematic target proteins}

Having validated the technique using the above proteins, we tested the applicability of the DPI to two proteins, one which has not given crystals after several years of trials and another which had been recalcitrant to producing crystals for several years and for which successful crystallisation conditions have recently been discovered.

Rat Dynamin. Rat dynamin does not crystallise despite extensive trials and is used here a negative control with $\mathrm{NaCl}$ as precipitant. Figure 6 shows the phase and contrast changes for the dialysis against sodium chloride. The phase increase observed corresponds solely to the increasing $\mathrm{NaCl}$ concentration and no protein deposition is observed. In fact the protein response does not increase as much as the control channel, indicating desorption of the initially adsorbed protein monolayer from the chip surface as a result of increasing salt concentration. This process can be seen to be starting to reverse as the salt is dialysed back out at the end of the experiment. The contrast in either channel does not drop during the whole experiment. 


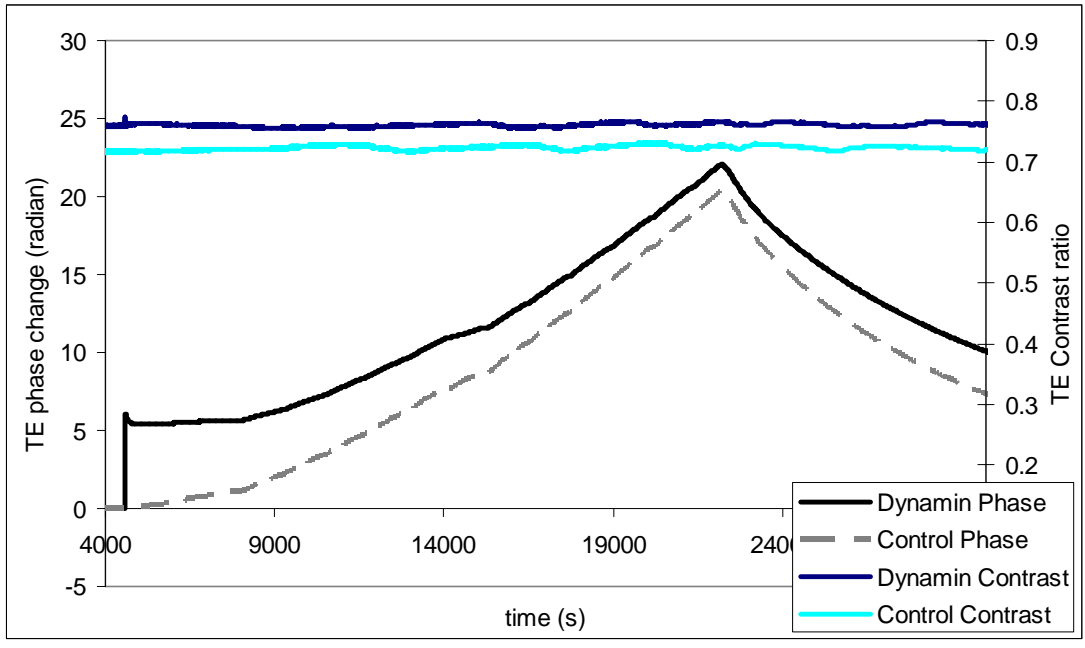

Figure 6. Phase and contrast for Rat Dynamin at $4.5 \mathrm{mg} / \mathrm{ml}$ dialysed against the same buffer containing $\mathrm{NaCl}$ to a final concentration of $2 \mathrm{M}$. The $\mathrm{NaCl}$ is then rinsed back out by dialysis against the buffer.

Xylanase. Xylanase is a target protein that had proved difficult to crystallise until recently, when this was achieved with crystals forming in $0.5 \mathrm{M}-1 \mathrm{M}$ ammonium sulphate and $50-100 \mathrm{mM} \mathrm{NaCl}$. Figure 7 shows the DPI with dialysis result for this crystallisation condition. Apart from the initial phase increase on introduction of the stock protein solution, due to bulk refractive index change from the protein and monolayer adsorption, the ammonium sulphate driven deposition of xylanase on the chip can be seen to start taking place at the arrow marked A. This corresponds to 0.5 $\mathrm{M}$ ammonium sulphate, as calibrated using the control channel response, and is at the lower end of the crystallisation conditions. The upper end of the range was $1 \mathrm{M}$ ammonium sulphate and is marked by the second arrow (B). The contrast is observed to start dropping just above this concentration, and the interference fringes are almost completely extinguished by the time the phase change has reached a plateau at $2.8 \mathrm{M}$ ammonium sulphate.

Crystals of xylanase could only be obtained by using unconventional crystallisation methods that allowed slow and well-controlled increase of the precipitant concentration in the crystallisation solution, namely capillary counterdiffusion ${ }^{12}$ and a modified version of vapour diffusion ${ }^{13}$. Crystallisation conditions were therefore altogether missed in standard vapour diffusion and microbatch trials. In contrast, the DPI with dialysis method, which is sensitive to the presence of microcrystals and 
allows the crystallisation process to be driven through a range of precipitant concentrations, was capable of clearly identifying a promising crystallisation condition.

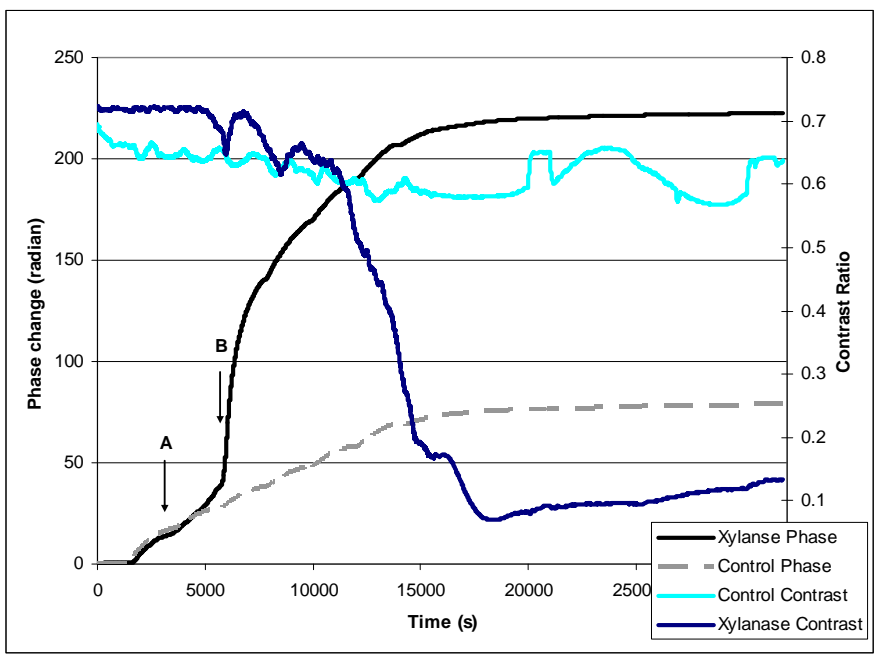

Figure 7. Phase and contrast for $12 \mathrm{mg} / \mathrm{ml}$ xylanase in $20 \mathrm{mM}$ Tris $\mathrm{HCl}, 100 \mathrm{mM} \mathrm{NaCl}, \mathrm{pH}$ 7.0, dialysed against 0.5 to $2.8 \mathrm{M}$ ammonium sulphate in $0.1 \mathrm{M}$ sodium cacodylate, $\mathrm{pH}$ 6.5, $100 \mathrm{mM} \mathrm{NaCl}$. The ammonium sulphate concentration in the protein channel reaches $2.75 \mathrm{M}$ during the experiment.

\section{Characteristic stages in the crystallisation process}

DPI measurements can further be used for the description of the crystallisation process. Studying the data in greater detail, it is possible to distinguish the different stages of protein adsorption, association and eventually crystallisation (if it occurs). The following stages are presented in the order they typically occur and can be observed by the present dialysis experiments.

A) Physisorption of protein to surface (small phase increase, Figure S2, Supporting Information).

B) Desorption of protein from surface due to electrostatic shielding of salt salting in (Figure 2).

C) Increase in bulk refractive index of the solution due to increasing salt concentration (phase increase - same slope for control and protein channels, Figure 2, 5-7\% NaCl). 
D) Association of protein at the surface (the slope of the phase change on the protein channel increases above that of the control channel, Figure 3, 3-11\% $\mathrm{NaCl})$

E) Loss of fringe contrast - Crystal Nucleation (Figures 3, 4, S3, Supporting Information)

F) Large / Rapid increase in phase shift - Protein precipitation (Figures 5, S4, Supporting Information)

G) Decrease in phase shift on incubation post-crystallisation is occasionally observed and could be attributed to dissolution of precipitate or microcrystals if larger crystals are growing outside the measurement path.

Some of the above phenomena can be summarized in the form of a phase diagram analogue. Figure 8 presents such a "phase diagram" (thin lines) for lysozyme, superimposed on a more traditional crystallisation phase diagram obtained by a fine screening of conditions in microbatch drops (thick lines). The latter was established as described in ${ }^{14,15}$. The arrow shows the direction in which the dialysis setup allows the conditions to be scanned, sampling across a wide range of the phase diagram.

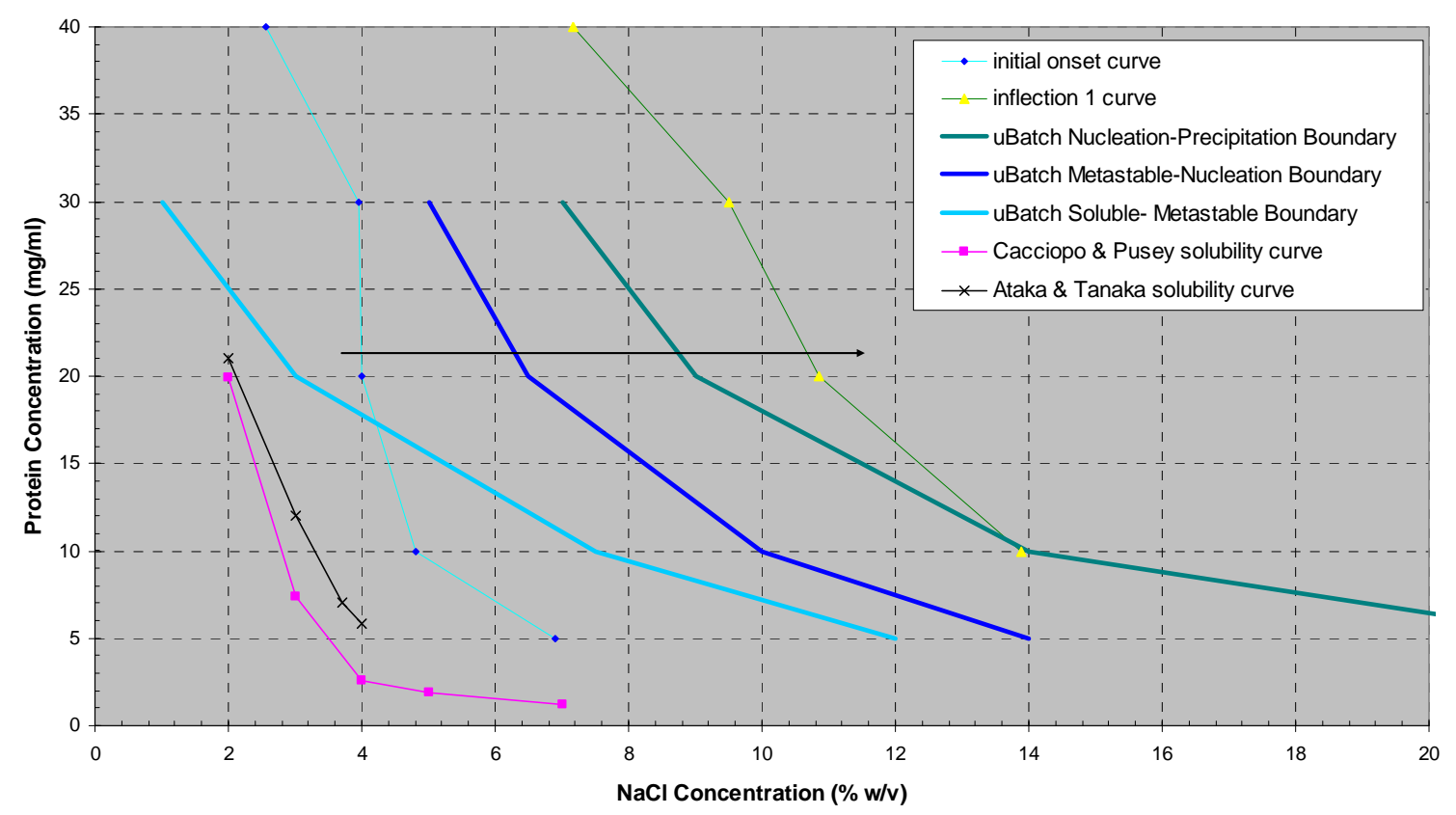

Figure 8. Phase diagram analogue obtained with DPI (thin lines) for lysozyme, compared with working phase diagram obtained in microbatch (thick lines) and with solubility data from Ataka \& Tanaka ${ }^{16}$ and Cacciopo \& Pusey ${ }^{17}$. 
The initial onset curve (Figure 8, in cyan) is the point where the phase shift on the protein channel starts increasing faster than the phase shift on the control channel (stage D above). It indicates the start of aggregation of the protein at the chip surface. This is expected to be somewhat above the soluble-metastable boundary (i.e. the solubility curve) but below the metastable-nucleation zone boundary (the supersolubility curve), since deposition of protein molecules on the chip surface requires supersaturation, but most probably at a lower level than that required for nucleation in the solution bulk. It is observed that at higher protein concentrations the initial onset curve is indeed at higher precipitant concentrations than the solublemetastable boundary obtained from microbatch experiments. The former though, displays a much sharper slope from $30 \mathrm{mg} / \mathrm{ml}$ to $10 \mathrm{mg} / \mathrm{ml}$ lysozyme; the two curves thus cross at $18 \mathrm{mg} / \mathrm{ml}$ protein and $4 \%(\mathrm{w} / \mathrm{v}) \mathrm{NaCl}$, after which the initial onset curve corresponds to lower precipitant concentrations than the microbatch solublemetastable boundary. However, comparison of the initial onset curve with solubility curves obtained by Ataka \& Tanaka $^{16}$ and by Cacciopo \& Pusey ${ }^{17}$ shows that the overall shape of these is much more similar to the initial onset curve than the corresponding microbatch curve. As expected, the initial onset curve is above the solubility curves determined both by Ataka \& Tanaka (at $15^{\circ} \mathrm{C}$ ) and by Cacciopo \& Pusey $\left(\right.$ at $20^{\circ} \mathrm{C}$ ), i.e. it corresponds to higher salt concentrations at solubility. Ataka \& Tanaka ${ }^{16}$ as well as Cacciopo \& Pusey ${ }^{17}$ use accurate methods of measuring the true solubility of the protein, consisting in re-dissolving crystals in undersaturated solutions as well as growing them in supersaturated ones. The method used in the microbatch experiments is a much faster one, which does not involve re-dissolving of crystals and leads to what has been dubbed a "working phase diagram". It appears that the DPI initial onset curve, whilst not coinciding with the solubility curve, may provide a useful indication of the overall features of the [precipitant]-[protein] dependency. Potentially, a true solubility curve could be obtained with this technique if, after nucleation has taken place, the dialysis were then reversed to determine the point at which the crystalline material starts redissolving.

The inflection 1 curve (Figure 8, in green) corresponds to the point at which the phase starts to increase rapidly (indicative of rapid aggregation, stage $\mathrm{F}$ above) thus it corresponds to the boundary of the precipitation region. At low protein concentration 
this corresponds closely with the microbatch values but at higher protein concentration it is at a higher salt concentration than the latter. This discrepancy could be expected due to the "shock nucleation" effect in microbatch at high protein concentrations, when nuclei form at the interface where the two highly concentrated protein and precipitant solutions come into contact. Shock nucleation leads to an underestimation of the salt concentrations needed for protein precipitation ${ }^{15}$.

\section{Conclusions}

With the DPI dialysis technique, it is possible with a fixed sample volume, to scan through a wide precipitant concentration range in a relatively short period of time. It can be used to monitor the initial adsorption of protein to the optical chip surface, salting-in, aggregation onto the surface, nucleation, precipitation and crystal formation, all as a function of precipitant concentration. Similar measurements could of course readily also be extended to additives or $\mathrm{pH}$, as well as temperature which can already be dynamically controlled with the instrumentation. The experiments performed in this study offer a strong indication that DPI may reliably distinguish between nucleation-crystallisation events and mere amorphous aggregation events. A DPI "signature" of crystallisation, namely a fairly sharp loss of contrast accompanying the phase shift, was a feature of all trials performed where crystals were obtained or which were close to conditions where crystals can be obtained. In contrast, no appreciable contrast loss occurred when the trials led to either clear solutions or amorphous precipitation.

This has been validated against three different model proteins and two target proteins which show different crystallizing, and non-crystallising, behaviours. DPI can therefore be used as a powerful diagnostic tool for discovering and selecting promising crystallisation conditions, for distinguishing microcrystalline from amorphous precipitate (a very difficult task even for experienced crystallographers), and for collecting useful information for crystal optimisation as well as for the study of crystallogenesis. 


\section{References}

(1) Chayen, N. E.; Saridakis, E. Nat. Methods 2008, 5, 147-153.

(2) Cross, G. H., Freeman, N. J.; Swann, M. J. In: Handbook of Biosensors and Biochips, Vol. 1; Marks, R. S., Lowe, C. R., Cullen, D. C., Weetall, H. H.; Karube, I., Eds.; Wiley: Hoboken, 2007; pp 549-568.

(3) Lane, T. J.; Fletcher, W. R.; Gormally, M. V.; Johal, M. S. Langmuir 2008, 24, $10633-10636$

(4) Karim, K., Taylor, J. D., Cullen, D. C., Swann, M. J.; Freeman, N. J. Anal. Chem. 2007, 79, 3023-3031.

(5) Boudjemline, A., Clarke, D. T., Freeman, N. J., Nicholson J. M.; Jones, G. R. J. Appl. Cryst. 2008, 41, 523-530

6) Cudney, B., Patel, S., Weisgraber, K., Newhouse, Y.; McPherson, A. Acta Cryst. 1994, $D 50,414-423$.

(7) Chayen, N. E., Saridakis, E., El-Bahar, R.; Nemirovsky, Y. J. Mol. Biol. 2001, $312,591-595$.

(8) Ko, T.-P., Day, J., Greenwood, A.; McPherson, A. Acta Cryst. 1994, D50, 813 825.

(9) de Vos, A. M., Hatada, M., Van der Wel, H., Krabbendam, H., Peerdeman, A. F.; Kim, S.-H. Proc. Natl. Acad. Sci. USA. 1985, 82, 1406-1409.

(10) Ogata, C. M., Gordon, P. F., de Vos, A. M.; Kim, S.-H. J. Mol. Biol. 1992, 228, 893-908.

(11) Green, A.A. J. Biol. Chem. 1932, 95, 47-66.

(12) Ng, J. D., Gavira, J. A.; Garcia-Ruiz, J. M. J. Struct. Biol. 2003, 142, 218-231.

(13) Nneji, G. A.; Chayen, N. E. J. Appl. Crystallogr. 2004, 37, 502-503.

(14) Saridakis, E.; Chayen, N. E. Biophys. J. 2003, 84, 1218-1222. 
(15) Saridakis, E. E. G., Shaw Stewart, P. D., Lloyd, L. F.; Blow, D. M. Acta Cryst. 1994, D50, 293-297.

(16) Ataka, M.; Tanaka, S. Biopolymers 1986, 25, 337-350.

(17) Cacioppo, E.; Pusey, M. L. J. Cryst. Growth 1991, 114, 286-292. 


\begin{tabular}{|c|c|c|c|c|}
\hline $\begin{array}{ll}\begin{array}{l}\text { Protein } \\
(\mathrm{mg} / \mathrm{ml})\end{array} & \text { conc. } \\
\end{array}$ & Precipitant & Result & Phase shift & $\begin{array}{l}\text { Contrast } \\
\text { drop }\end{array}$ \\
\hline \multicolumn{5}{|c|}{ Lysozyme (in 50 mM Na acetate, pH 4.6) } \\
\hline 5 & $1-19 \%(w / v) \mathrm{NaCl}$ & clear & $\begin{array}{l}\text { Yes } \\
\text { (gradual) }\end{array}$ & No \\
\hline 10 & $1-20 \%(w / v) \mathrm{NaCl}$ & crystals & Yes & Yes \\
\hline 20 & $1-17 \%(w / v) \mathrm{NaCl}$ & crystals & Yes & Yes \\
\hline 30 & $1-13 \%(w / v) \mathrm{NaCl}$ & crystals & Yes & Yes \\
\hline \multicolumn{5}{|c|}{ Catalase (in 100 mM Tris, pH 7.5) } \\
\hline 12 & $30 \%(w / v)$ PEG 6000 & crystals & Yes & Yes \\
\hline 14 & $30 \%(w / v)$ PEG 6000 & crystals & Yes & Yes \\
\hline 14 & $30 \%(\mathrm{w} / \mathrm{v}) \mathrm{NaCl}$ & clear & Marginal & No \\
\hline \multicolumn{5}{|c|}{ Thaumatin (in 50 mM PIPES, pH 6.8) } \\
\hline 10 & $0.1-2.0 \mathrm{M} \mathrm{Na} / \mathrm{K}$ tartr. & crystals & Yes & Yes \\
\hline 15 & $0.1-1.6 \mathrm{M} \mathrm{Na} / \mathrm{K}$ tartr. & crystals & Yes & Yes \\
\hline 25 & $0.1-1.8 \mathrm{M} \mathrm{Na} / \mathrm{K}$ tartr. & crystals & Yes & Yes \\
\hline 40 & $\begin{array}{l}0.5-3.0 \mathrm{M} \text { amm. } \\
\text { sulphate }\end{array}$ & $\begin{array}{l}\text { microcrystals } \\
\text { (see text) }\end{array}$ & Yes & Yes \\
\hline 16 & $0.5-2.5 \mathrm{M} \mathrm{NaCl}$ & precipitation & Yes & No \\
\hline \multicolumn{5}{|c|}{ Dynamin (in 20mM PIPES pH 7, 1mM EGTA, 150 mM NaCl, 2 mM MgCl ) } \\
\hline 4.5 & $0.15-2 \mathrm{M} \mathrm{NaCl}$ & clear & No & No \\
\hline \multicolumn{5}{|c|}{ Xylanase (in $20 \mathrm{mM}$ Tris pH 7, 100mM NaCl) } \\
\hline 12 & $\begin{array}{l}0-2.8 \mathrm{M} \text { amm. } \\
\text { sulphate }\end{array}$ & microcrystals & Yes & Yes \\
\hline
\end{tabular}

Table 1. Summary of the crystallisation trials and corresponding DPI observations. 